\title{
Thermodynamic analysis of a gas turbine combined cycle integration with a high- temperature nuclear reactor
}

\author{
Marek Jaszczur ${ }^{1}$, Michat Dudek \\ ${ }^{1}$ AGH University of Science and Technology, Faculty of Fuels and Energy, Department of \\ Fundamental Research in Energy Engineering, A. Mickiewicza 30, 30-059 Kraków, Poland
}

\begin{abstract}
The recently a large number of various companies from the energy sector have to follow new very restrictive regulations which protect the natural environment against pollution and degradation. At the same time, the efficiency of energy conversion and the cost of energy remain important economic aspects. One of the solutions for today's challenges can be power generation based on Gas Turbine Combined Cycle proposed in this paper which is the most efficient and environmentally friendly cycle. What is more important this solution can be easily integrated with a High-Temperature nuclear Reactor. The proposed in this work systems consist of the reactor combined with a gas turbine as well as steam turbine. The results show that it is possible to obtain for proposed cycle an efficiency higher than $50 \%$ which is not only more than could be offered by traditional coal power plant but much more than can be proposed by any other nuclear technology.
\end{abstract}

\section{Introduction}

The significant reduction of greenhouse gases, harmful gases and $\mathrm{CO}_{2}$ generated by the energy system is, in present days the centre of energy-related discussions in the European Union. With the target to enhance the $\mathrm{CO}_{2}$ reduction, the European Commission presented in 2018 "Long-term Climate Strategy", and specified the major target "Climate Neutral economy by 2050" [1]. Significant progress has been observed in transforming energy production in Europe. At present approximately $50 \%$ of Europe's electricity production is greenhouse gas emissions free and the aim is to have more than $80 \%$ by 2050 . Nuclear power plants possess about $15 \%$ of this production [2-4] and the European transition is similar to global ones proposed by the Intergovernmental Panel on Climate Change report [1]. Besides renewable energy systems which supply with success energy systems in many countries, at present, the most effective technology for stable electricity generation is based on a gas turbine combined cycle (GTCC). In particular closed-cycle gas turbine power plants have a large potential to complement the traditional coal-based power plant as well as power plants based on internal combustion gas turbine [5]. Gas turbine plant in a typical way uses natural gas but it can also use synthesis gas as a product from the coal gasification or oil industry.

${ }^{1}$ Corresponding author: jaszczur@agh.edu.pl 
However, such a system if not properly design can generate a significant amount of nitrogen oxides, sulphur oxides and $\mathrm{CO}_{2}$ to the atmosphere. In order to enhance the system operation and efficiency the gas turbine combined cycle proposed employs gas turbine (GT) and heat recovery steam generator that uses exhaust gases to produce high-quality steam to a steam turbine [6]. However, to develop a zero-emission and efficient technology, the integration with the technology of high-temperature nuclear reactors seems to be the only a primary direction $[7,8]$. The program to develop the HTR with a gas helium coolant is a technological cornerstone for advanced applications that further expand the safe use of nuclear energy [911]. A new generation of high temperature gas-cooled nuclear reactors is the most innovative concept among all advanced nuclear reactor technologies. The U.S. Department of Energy created a program to develop the high and very high-temperature gas-cooled reactors (HTR, VHTR) for advanced applications that expand the safe use of nuclear energy. Such nuclear reactors possess a large number of fundamental characteristic features that significantly distinguish them from already available reactors. In particular, the fuel in this reactor type is in the form of small ceramic coated particles TRISO able to operate at a temperature above $1250^{\circ} \mathrm{C}$. Additionally, the helium gas is used as a working fluid and the moderator is constructed from graphite [12-13]. The HTR is designed for the outlet fluid temperature above $850-900^{\circ} \mathrm{C}$ and in the case of VHTR above $900-1000^{\circ} \mathrm{C}$. These features provide the potential for higher energy conversion efficiency and for process heat applications for high-temperature industrial application [14,15]. In the opinion of many experts, the most promising technology that could be implemented in the energy industry in near future is the technology based on HTRs, which are perfect solution for the electrical energy production and process heat.

In this work, the authors propose new designs of gas turbine combined cycle coupled with a high-temperature nuclear reactor. The aim of the present work is to find the optimal configuration for the cycle with single, dual, and triple pressure Heat Recovery Steam Generator units, steam regeneration cycle and optional cogeneration.

\section{Mathematical model and assumptions}

The mathematical model for the analysed power cycle consists of the thermodynamic equations for High-Temperature Nuclear Reactor coupled with gas turbine combined, heat recovery steam generation and steam turbine with steam regeneration [16]. The thermal cycle has been presented in Figure 1. Thermal reactor (HTR) power was calculated as follow:

$$
\dot{Q}_{r}=\dot{m}_{H e} c_{p H e}\left(T_{\text {out }}-T_{\text {in }}\right)
$$

where: $m_{1 H e}$ - helium mass flow rate, $c_{p H e}$ - helium specific heat, $T_{\text {out }}$ - reactor outlet temperature, $T_{i n}$ - reactor inlet temperature. The heat flux supplied in the primary circuit is:

$$
\dot{Q}_{r}=\dot{m}_{H e}\left(h_{1}-h_{2}\right)
$$

where: $h_{1}, h_{2}$ - helium specific enthalpy at the inlet to/outlet from the heat exchanger hot side. The heat flux received in the second circuit:

$$
\dot{Q}_{R}=\dot{m}_{2 H e}\left(h_{4}-h_{3}\right)
$$

where: $m_{2 H e}$ - helium mass flow rate, $h_{4}$ - enthalpy at the outlet from the heat exchanger cold side, $h_{3}$ - enthalpy at the inlet to the heat exchanger cold side.

High-temperature heat exchanger (IHX) enthalpy balance: 
$\dot{m}_{1 \mathrm{He}} c_{p \mathrm{pe}}\left[T_{1}-T_{0}\right]+\dot{m}_{2 \mathrm{He}} c_{p \mathrm{He}}\left(T_{3}-T_{0}\right)=\dot{m}_{1 \mathrm{He}} c_{p \mathrm{He}}\left(T_{2}-T_{0}\right)+\dot{m}_{2 \mathrm{He}} c_{p \mathrm{He}}\left(T_{4}-T_{0}\right)$

where: $m_{1 \mathrm{He}} / m_{2 \mathrm{He}}$ - helium mass flow at the hot/cold side, $T_{1} / T_{2}$-inlet/outlet temperature to/from heat exchanger - hot side, $T_{3} / T_{4}$ - inlet/outlet temperature to/from heat exchanger cold side, $T_{0}$ - reference temperature.

Gas turbine (GT) electrical power was calculated from the following equation:

$$
N_{G T 1}=\eta_{\text {gen }} \dot{m}_{2 H e}\left(\eta_{\mathrm{i} G T} \eta_{\text {mech }} w_{G T}-w_{C} /\left[\eta_{i C} \eta_{\text {mech }}\right]\right)
$$

where: $\eta_{g e n}$ - electrical efficiency, $\eta_{\mathrm{i} G T}$ - gas turbine isentropic efficiency, $\eta_{i C}$ - compressor isentropic efficiency, $\eta_{\text {mech }}$ - mechanical efficiency, $w_{G T}$ - gas turbine work, $w_{C}-$ compressor work.

Steam turbine electrical power was calculated as follows:

$$
N_{S T}=\eta_{\text {gen }} \eta_{\text {mech }}\left(\sum_{i=1}^{2} \eta_{i} \eta_{\text {mech }} \dot{m}_{p i} w_{i}\right)-\sum_{i=1}^{2}\left[\left(\dot{m}_{w i} w_{p i}\right) /\left(\eta_{i p} \eta_{\text {mech }}\right)\right]
$$

where: $\eta_{g e n}$ - generator efficiency, $\eta_{\text {mech }}$ - mechanical efficiency, $\eta_{i}$ - isentropic steam turbine efficiency, $\eta_{i p}{ }^{-}$isentropic pump efficiency, $\dot{m}_{p i}{ }^{-}$steam mass flow rate, $w_{i}-$ high/middle/low-pressure steam turbine work, $w_{p i}$ - water pumps work, $\dot{m}_{w i}$ - water mass flow. The thermal efficiency with and without cogeneration was calculated as follow:

$$
\eta_{c}=\frac{N_{G T}+N_{S T}+\eta \dot{Q}_{C O G}-\sum_{i / 1}^{n} N_{p i}-N_{b}}{Q_{R}} \text { or } \quad \eta_{c}=\frac{N_{G T}+N_{S T}-\sum_{i / 1}^{n} N_{p i}-N_{b}}{Q_{R}}
$$

where: $N_{g t 1}$ - gas turbine electrical power, $N_{s t i}$-first/second/third step steam turbine electrical power, $N_{b}$ - blower energy demand, $N_{p i}$ - pumps energy demand.

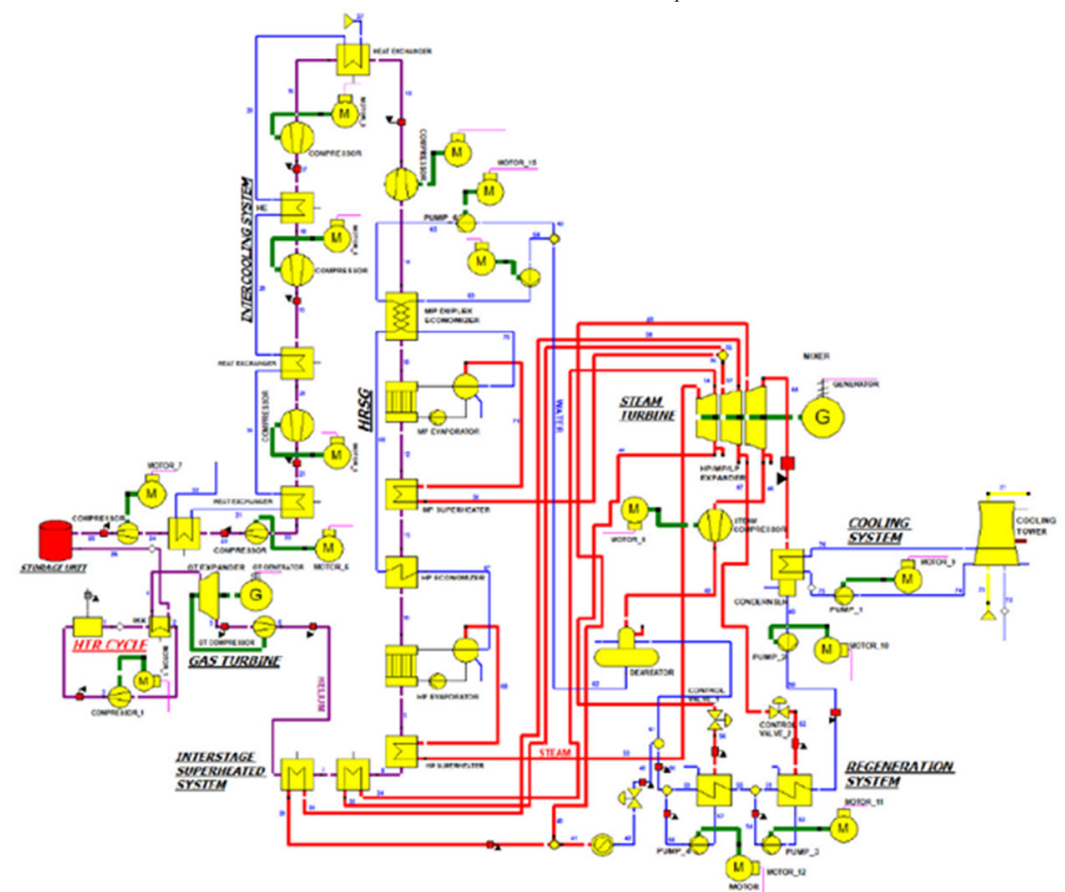

Fig. 1. High-temperature reactor coupled with a gas turbine combined cycle and with dual HRSG unit 
The model assumptions for thermodynamic calculations and additional model equation for selected components of the cycle are presented in Table 1. The calculations were made using Ebsilon software. The detailed information about all used system components and governing equations can be found in other authors research studies $[4,6,16]$.

Table 1. Assumptions for thermodynamic calculations.

\begin{tabular}{|c|c|c|}
\hline \multicolumn{3}{|c|}{ Assumptions for calculations } \\
\hline Thermal Power of HTR & 300 & $\mathrm{MW}_{\text {th }}$ \\
\hline Coolant in the main primary loop & $\mathrm{He}$ & - \\
\hline Working fluid in the secondary loop & $\mathrm{He}$ & - \\
\hline Reactor outlet temperature & 850 & ${ }^{\circ} \mathrm{C}$ \\
\hline Reactor coolant pressure & 7 & $\mathrm{MPa}$ \\
\hline The mass flow rate of helium in the primary loop & 128 & $\mathrm{~kg} / \mathrm{s}$ \\
\hline Inlet pressure before Gas Turbine & 6.95 & $\mathrm{MPa}$ \\
\hline Outlet pressure after Gas Turbine & 2 & $\mathrm{MPa}$ \\
\hline The mass flow rate of helium in the secondary loop & 104.5 & $\mathrm{~kg} / \mathrm{s}$ \\
\hline Gas Turbine mechanical efficiency & 0.99 & - \\
\hline Gas Turbine isentropic efficiency & 0.9 & - \\
\hline The steam Turbine inlet temperature & 385 & - \\
\hline Steam Turbine inlet pressure & 20.5 & $\mathrm{MPa}$ \\
\hline The mass flow rate of steam & $35.80 / 49.98 / 60.19$ & $\mathrm{~kg} / \mathrm{s}$ \\
\hline Steam turbine mechanical efficiency & 0.998 & - \\
\hline Steam turbine isentropic efficiency & 0.88 & \\
\hline Generator electric efficiency & 0.9856 & - \\
\hline The outlet temperature of water from the condenser & 23.96 & ${ }^{\circ} \mathrm{C}$ \\
\hline Pressure inlet at feed water preheater & $0.5 / 0.9$ & $\mathrm{bar}$ \\
\hline
\end{tabular}

In the presented system, the Heat Recovery Steam Generator (HRSG) is a key system component and any modification in this component affects significantly the efficiency of the steam turbine loop and the overall system efficiency. The highest heat transfer takes place in the evaporator part for the high-pressure level and in the economiser part for the low-pressure level. The remaining significant amount of heat delivery by exhaust gases from the gas turbine can be used in an HRSG unit in order to produce high-quality steam for the steam turbine. HRSG units are usually classified based on the number of drums in the boiler. In the presented system single (1P), dual (2P) and triple (3P) pressure Heat Recovery Steam Generator units are used with steam regeneration units to show its impact on the final results. A detailed numerical model for designing the HRSG unit with heat transfer correlations can be found in [6].

\section{Results}

The analysed system is based on the layout of GTCC with dual pressure heat recovery steam generation system coupled with HTR and presented in Fig. 1 with various sub-configurations. As can be seen from results presented in Fig.2(a)-(c) system is able to generate more than $215.84 \mathrm{MW}_{\mathrm{e}}$ of electricity. However, when the system is equipped with single or triple HRSG unit electrical energy production obtained from numerical calculations equals to $207.22 \mathrm{MW}_{\mathrm{e}}$ and 228.29 $\mathrm{MW}_{\mathrm{e}}$ respectively what is shown in Figure 2(a). One may infer from this figure significant increase in the power when two or three pressure heat recovery steam generation unit is implemented. The presented system without cogeneration is able to generate electricity with thermal efficiency in the range from $36.6 \%, 40.6 \%$ up to $46.02 \%$ depending on the exact sub-solution i.e. (1P, 2P, 3P) pressure level Heat Recovery Steam Generator (HRSG) respectively - see Fig.2(c). On the other hand for the systems with cogeneration gas turbine, electrical power productions remain the same but energy production by the steam turbine is 
slightly lower. The system presented in Fig. 1 and sub-configuration with cogeneration generate about 194.25, 204.55 and $214.21 \mathrm{MW}_{\mathrm{e}}$ of electrical power for 1P, 2P and 3P HRSG respectively what is shown in Fig. 2(d)-(f). The system thermal efficiency with cogeneration and sub-configuration with single, dual or triple HRSG unit obtain higher overall thermal efficiency $47.6 \%, 52.7 \%$ and $56.3 \%$ respectively. In Figures $3(\mathrm{a})$-(b) for part of the cycle q,T diagrams are presented for the 1P, 2P HRSG configuration and for the Cold Side and Hot Side.
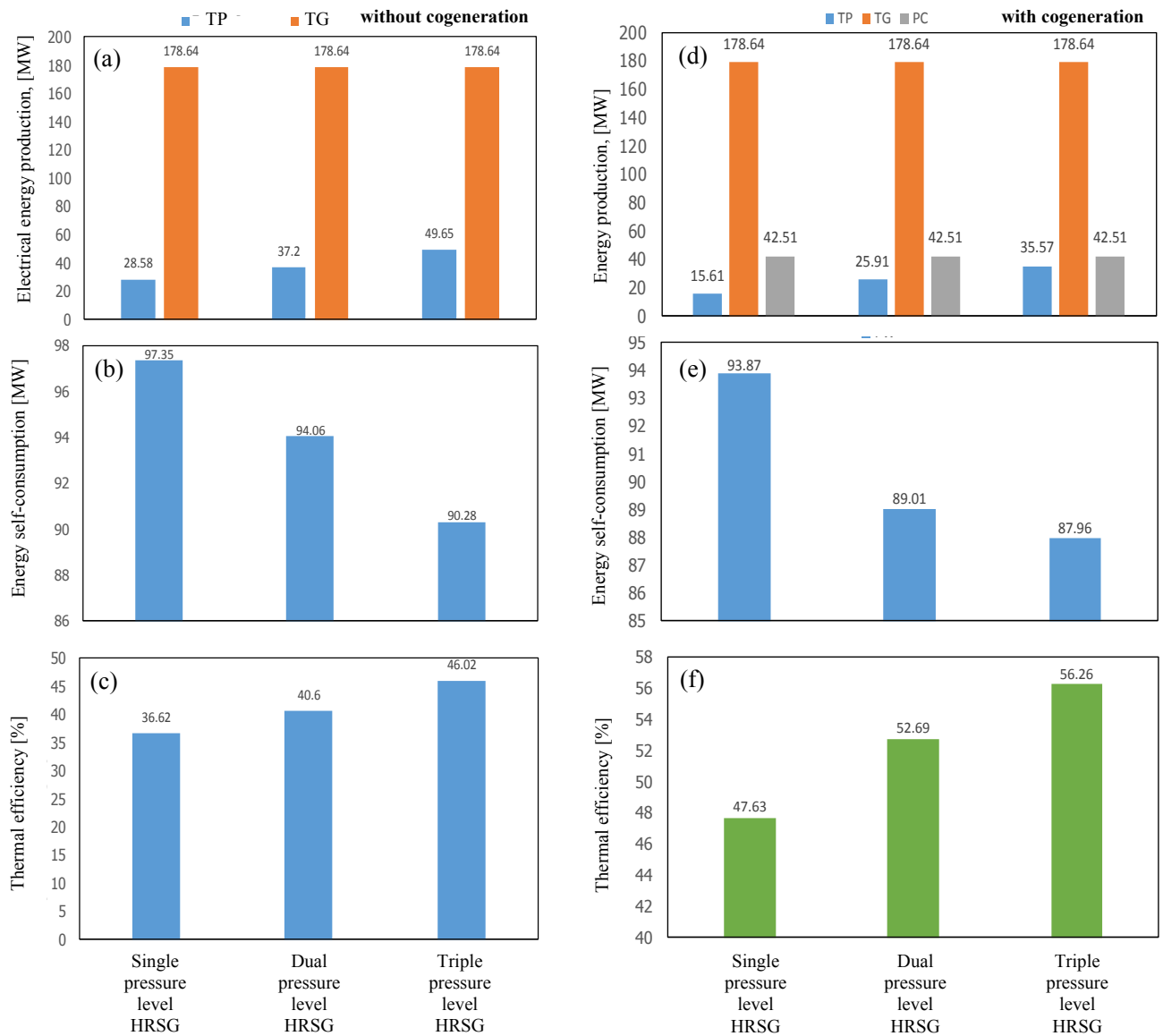

Fig. 2. Electrical (or heat) energy production from gas turbine and steam turbine (a,d), energy selfconsumption $(\mathrm{b}, \mathrm{e})$ and overall system thermal efficiency $(\mathrm{c}, \mathrm{f})$ for the system with $1 \mathrm{P}, 2 \mathrm{P}, 3 \mathrm{P}$ pressure level HRSG and without cogeneration (left) with cogeneration (right).
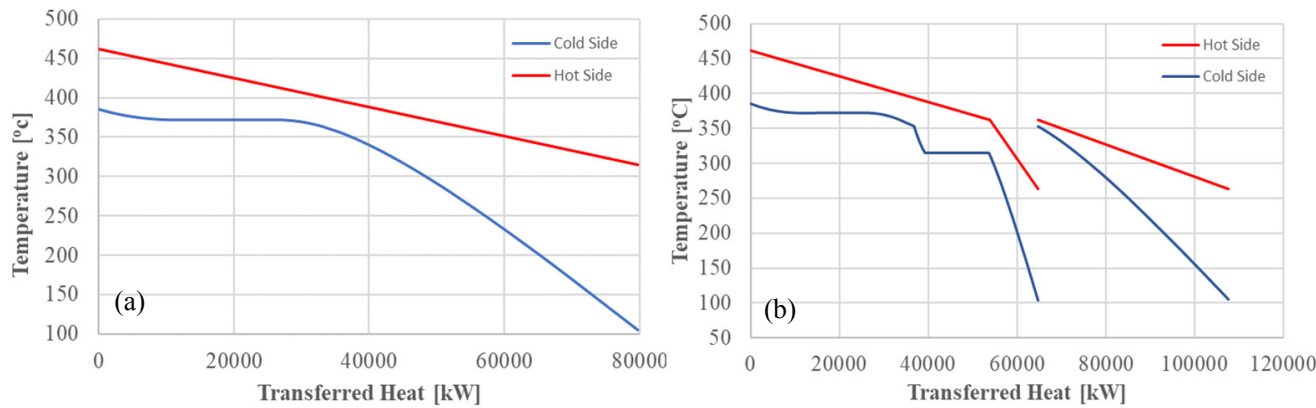

Fig. 3. The q, T diagrams for the 1P (a) and 2P (b) HRSG configuration and for the Cold Side and Hot Side (system without cogeneration). 


\section{Conclusions}

The GTCC coupled with High-Temperature Nuclear Reactor is a very attractive solution in the field of emission-free energy production and highly efficient power plant technology. The industrial implementation of such systems is able to generate electricity with very high thermal efficiency depending on the exact sub-solution including cogeneration, regeneration, 1P (single pressure), 2P (dual pressure) and (3P) triple pressure-level Heat Recovery Steam Generator. The presented solution it is based on one of the most advanced technologies which give the opportunity to produce electricity and technological heat without any emissions of greenhouse gasses and with thermal efficiency higher than a classical coal-fired power plant or a classical nuclear power plant technology such as PWR, BWR.

Power cycle analysis shows that it is possible to obtain for a cycle without cogeneration and most economical solution with dual pressure-level Heat Recovery Steam Generator thermal efficiency equal to $40.6 \%$ system with triple pressure-level HRSG unit offer efficiency 6 p.p. however it is not always economically justified. On the other hand, 2P HRSG system with cogeneration can obtain efficiency as high as $52.7 \%$.

Acknowledgement: The present work was partially supported by the Polish Ministry of Science (Grant AGH No. 16.16.210.476).

\section{References}

1. World Energy Council, World Energy Resources (2016)

2. Z. Liu, I. A. Karimi, Energy Convers. Manag. 171, 1675 (2018)

3. Q. Xinhe, Y. Xiaoyong, W. Jie, Z. Gang, Prog. Nucl. Energy, 108, 1 (2018)

4. M. Jaszczur, M. Dudek, Z. Kolenda, Thermal Science, 4, 17 (2019)

5. International Atomic Energy Agency, Power Reactor Information System

6. M. Dudek, J. Podsadna, M. Jaszczur, J. of Phys.: Conf. Ser. 745, 032009 (2016)

7. Y. Shin et al., Appl. Energy 173, 460 (2016)

8. IAEA, High Temperature Gas Cooled Reactor Fuels and Materials, IAEA 1 (2010)

9. Z. Zhang, et al., Engineering 2, 112 (2016)

10. Next Generation Nuclear Plant Research and Development Program Plan, Idaho National Laboratory, (2005)

11. S.K. Mylavarapu et al., Appl. Thermal Eng. 65, 605 (2014)

12. International Prismatic Block HTGR Commercial Deployment Meeting Summary in Washington DC, (2016)

13. A. C. Kadak, Engineering 2, 119 (2016)

14. M. Dudek, Z.Kolenda, M.Jaszczur, W.Stanek, J. Energy Resour Technol 140, 20910(2018)

15. M. Jaszczur, M. A. Rosen, T. Śliwa, M. Dudek, L. Pieńkowski, Int. J. Hydrogen Energy 41, 7861 (2016)

16. M. Jaszczur, M. Dudek, T. Śliwa,Z. Kolenda, MATEC Web ofConf. 240, 05010 (2018) 